\title{
1 Spatio-temporal variability of water pollution by 2 chlordecone at the watershed scale: what insights for the management of polluted territories?
}

Charles MOTTES ${ }^{1,2, *}$, Landry DEFFONTAINES ${ }^{1,2}$, Jean Baptiste CHARLIER ${ }^{3}$, Irina COMTE $^{2,4}$, Pauline DELLA ROSSA ${ }^{1,2}$, Magalie LESUEUR-JANNOYER ${ }^{1,2}$, Thierry WOIGNIER $^{5}$, Georges ADELE ${ }^{6}$, Anne-Lise TAILAME7 ${ }^{7}$ Luc ARNAUD ${ }^{7}$, Joanne PLET ${ }^{1,2}$, Luc RANGON ${ }^{5}$, Jean-Pierre BRICQUET $^{6}$, Philippe CATTAN ${ }^{2,4}$.

${ }^{1}$ Cirad, UPR HortSys, F-97285 Le Lamentin, Martinique, France

${ }^{2}$ HortSys, Geco, Univ Montpellier, Cirad, Inra, Inria, Montpellier SupAgro, Montpellier, France.

${ }^{3}$ BRGM, Univ. Montpellier, Montpellier, France

${ }^{4}$ Cirad, UPR GECO, F-34000 Montpellier, France

${ }^{5}$ Aix Marseille Université, Avignon université, IRD, CNRS, IMBE, F-97285 Le Lamentin, Martinique, France

${ }^{6}$ IRD, HSM, F-97285 Le Lamentin, Martinique, France

${ }^{7}$ BRGM, F-97200 Fort-de-France, Martinique, France

* Corresponding author : charles.mottes@ cirad.fr, Phone : +596 596423073, Fax: +596 596423001

\begin{abstract}
Chlordecone, applied on soils until 1993 to control banana weevil, has polluted waters resources in the French West Indies for more than 40 years. At the watershed scale, chlordecone applications were not homogenous, generating a spatial heterogeneity of the pollution. The roles of climate, hydrology, soil, agronomy and geology on watershed functioning generate a temporal heterogeneity of the pollution. This study question the interactions between practices and the environment that induce such variability. We analyzed hydrological and water pollution datasets from a two years monitoring program on the Galion watershed in Martinique (French West Indies). We conjointly analyzed: i) weekly CLD concentration monitored on 3 river sampling sites, ii) aquifer piezometric dynamics and pollutions, and iii) agricultural practices on polluted soils. Our results showed that chlordecone pollution in surface waters are characterized by annual trends and infra-annual variations. Aquifers showed CLD concentration 10 times higher than surface water, with CLD concentration peaks during recharge events. We showed strong interactions between rainfall events and practices on CLD pollution requiring a systemic management approach, in particular during post cyclonic periods. Small sub-watershed with high CLD pollution, appeared to be substantial contributor to CLD mass transfers to the marine environment via rivers, and should therefore receive priority management. We suggest increasing stable organic matter return to soil as well as external input of organic matter to reduce CLD transfers to water. We identified hydrological conditions - notably drying periods - and tillage as the most influential factors on CLD leaching. In particular, tillage acts on 3 processes that increases CLD leaching: organic matter degradation, modification of water paths in soil and allophane clay degradation.
\end{abstract}

\section{Keywords}

Chlordecone, pollution, observatory, hydrology, environment, management, practices 
42 This work was made possible thanks to the financial support of the National Chlordecone Action Plan 43 (PNAC), French Water Office of Martinique (ODE Martinique) and European Regional Development 44 Fund (FEDER) with the RIVAGE project (MQ0003772-CIRAD). We also thank F. Massat and P. Rey 45 from LDA26 for providing details on the protocols from the laboratory. 


\section{Introduction}

The protection of surface and groundwater resources from pesticide pollutions is a remaining challenge. Such question is a live issue in tropical volcanic island and especially in the French West Indies (FWI) where organochlorine pesticide, namely chlordecone $\left(\mathrm{CLD} ; \mathrm{C}_{10} \mathrm{Cl}_{10} \mathrm{O}\right.$; CAS number 143-50-0; 491 g. $\mathrm{mol}^{-1}$ ) was used in agriculture in Guadeloupe and Martinique islands. CLD was applied from 1972 to 1993 to control the black banana weevils (Cosmopolites sordidus). Since a few decades, it pollutes soils, surface waters and groundwaters in a chronic manner. CLD is a very stable pesticide that shows a very slow degradation rate that is not evenly quantifiable (Cabidoche et al. 2009; Clostre et al. 2015; Devault et al. 2016). Because of the very high affinity of chlordecone with soil organic matter -Koc ranging from 1200 to 17500 L.kg $^{-1}$ (Cabidoche et al. 2009; Fernandez-Bayo et al. 2013a)-, only small fractions of the soil CLD amounts are drained by infiltrated water. However, despite its low mobility, the drained fraction of CLD was enough to highly contaminate other environmental compartments, such as aquifers and rivers (Cabidoche et al. 2009; Cattan et al. 2019; Charlier et al. 2015; Crabit et al. 2016; Della Rossa et al. 2017; Gourcy et al. 2009; Mottes et al. 2015). Several crops grown on polluted soils might as well be contaminated depending on their nature (Clostre et al. 2017). Such pollution of food and water exposed population to sanitary issues (Multigner et al. 2016). In order to face the problem, strategies were developed to limit the exposure of the population: drinking water is treated using active carbon (Ranguin et al. 2017) and decision rules were developed for cropping crops depending on their sensitivity to CLD pollution from soil (Clostre et al. 2017). The development of such management strategies were helpful to reduce the exposure of the population to the pesticide.

Chlordecone was found into aquatic coastal fauna (Dromard et al. 2018) and until pelagic cetacean (Méndez-Fernandez et al. 2018). Such results suggest subsequent amount of CLD transferred into the sea and raises the question of the sources, questioning the past or the present provenance of such contamination. It is known that soils are still the main CLD storage (Lesueur-Jannoyer et al. 2012; Levillain et al. 2012) and that CLD transfers from soils to the other environmental compartments is governed by water flows (Mottes et al. 2016). To that point, CLD behavior in soils has been investigated (Cabidoche et al. 2009; Clostre et al. 2015; Fernandez-Bayo et al. 2013a; Fernandez-Bayo et al. 2013b), especially, the effect of the allophanic clay of andosols favoring CLD retention in soil (Woignier et al. 2012a), or the effect of added organic matter on CLD transfers (Woignier et al. 2012b).

All of these characteristics draw a complex system whose evolution is difficult to assess. On that topic, Cattan et al. (2019) analyzed the spatio-temporal variability of CLD and its main metabolite (CLD-5bhydro) in FWI. Authors showed significant decreasing trends of CLD concentrations in waters on some large watersheds. This is consistent with general literature on pesticides: because CLD is not applied anymore, one may expect slowly decreasing concentration in the terrestrial environment. However, because of the very low degradability of CLD, authors highlighted that the pluri-annual CLD decrease in leaching water was likely mostly generated by CLD transfer to another compartment rather than its degradation. This forces us analyzing jointly CLD concentration in the environmental compartments that are related to each other in order to understand the CLD exportation from the watershed system. According to the literature, several factors modify pesticides transfers at the watershed scale: climate, hydrogeological context, cropping practice, soil properties as well as the interaction between these factors (Lewis et al. 2016; Mottes et al. 2014; Mottes et al. 2017). Evolution of CLD concentrations in rivers may also show different variabilities depending on the time and space scales considered. Previous studies showed that CLD seasonnal dynamics varied with the strong contributions of unpolluted water from a forested upstream sub-watershed (Crabit et al. 2016). Gourcy et al. (2009) showed that groundwater residence times in aquifers last from years to decades in FWI. We expect that such long residence times may result in long-term evolution of CLD in rivers.

In this study, we aimed to characterized factors that determine CLD transfer outside the watershed system. Given that CLD is mainly exported through rivers, we focused on the conjoint analysis of agricultural practices and the evolution of CLD into surface and groundwater. We considered the case 
of the Galion watershed in Martinique (FWI). This watershed is monitored to survey CLD pollutions in surface and underground water compartments. First, we identified trends and variabilities of CLD concentration in the different environmental compartments monitored. Second, we discussed factors that may have influenced the modification of CLD concentrations in both, rivers and aquifers. Third, we assess the contribution of different sub-watersheds to CLD transfers into the sea (Galion bay). Finally, we propose strategies to prioritize actions and to help reduce CLD transfers into the environment.

\section{Materials and Methods}

\subsection{Study site}

The Galion river watershed $\left(61^{\circ} 4.4004^{\prime} \mathrm{W} / 14^{\circ} 36.5352^{\prime} \mathrm{N}\right)$ is located on the East coast of the Martinique, a volcanic island in the French West Indies. This watershed is part of the OPALE observatory (Observatoire des Pollutions Agricoles aux Antilles - Observatory for agricultural Pollutions in Antilles). It was selected for its representativeness of the various agropedoclimatic conditions of Martinique.

The watershed covers $44.5 \mathrm{~km}^{2}$ ranging from altitudes 0 to $694 \mathrm{~m}$ above sea level. The climate is humid tropical with oceanic influence. Rainfall range from $1500 \mathrm{~mm} \cdot \mathrm{y}^{-1}$ downstream up to $4000 \mathrm{~mm} \cdot \mathrm{y}^{-1}$ upstream. The hydrosystem is composed of 4 major permanent watercourses and a very dense network of intermittent gullies (Figure 1).

Steep slopes $(>80 \%)$ with tropical forest and agricultural land for livestock and traditional food production characterize the watershed upstream. The soils are volcanic ash soils (andosol) characterized by high infiltration rates (Cattan et al. 2006) and high organic matter concentration (Dorel et al. 2000). Soft slopes $(\sim 35 \%)$ cropped with banana and mixed farming on intergrade soils between andosol and compact ferralsol characterize the intermediate zone. A flood plain characterize the downstream zone where industrial crop productions, including banana and sugar cane, take place on ferralsols (Figure 1).

The bedrock is composed of volcanic formations of andesitic type (Germa et al. 2011). Geological formations are thus composed by ash flows, lava flows, and reworked formations as well as atmospheric fallout on a larger scale. Such geology generates a high spatial variability of lithology strata and contrasting weathering levels between geological units. Consequently, volcanic aquifer's units have small dimensions of a few square kilometres at most, generating complex groundwater flows according to more or less permeable materials (Charlier et al. 2011; Vittecoq et al. 2015). 


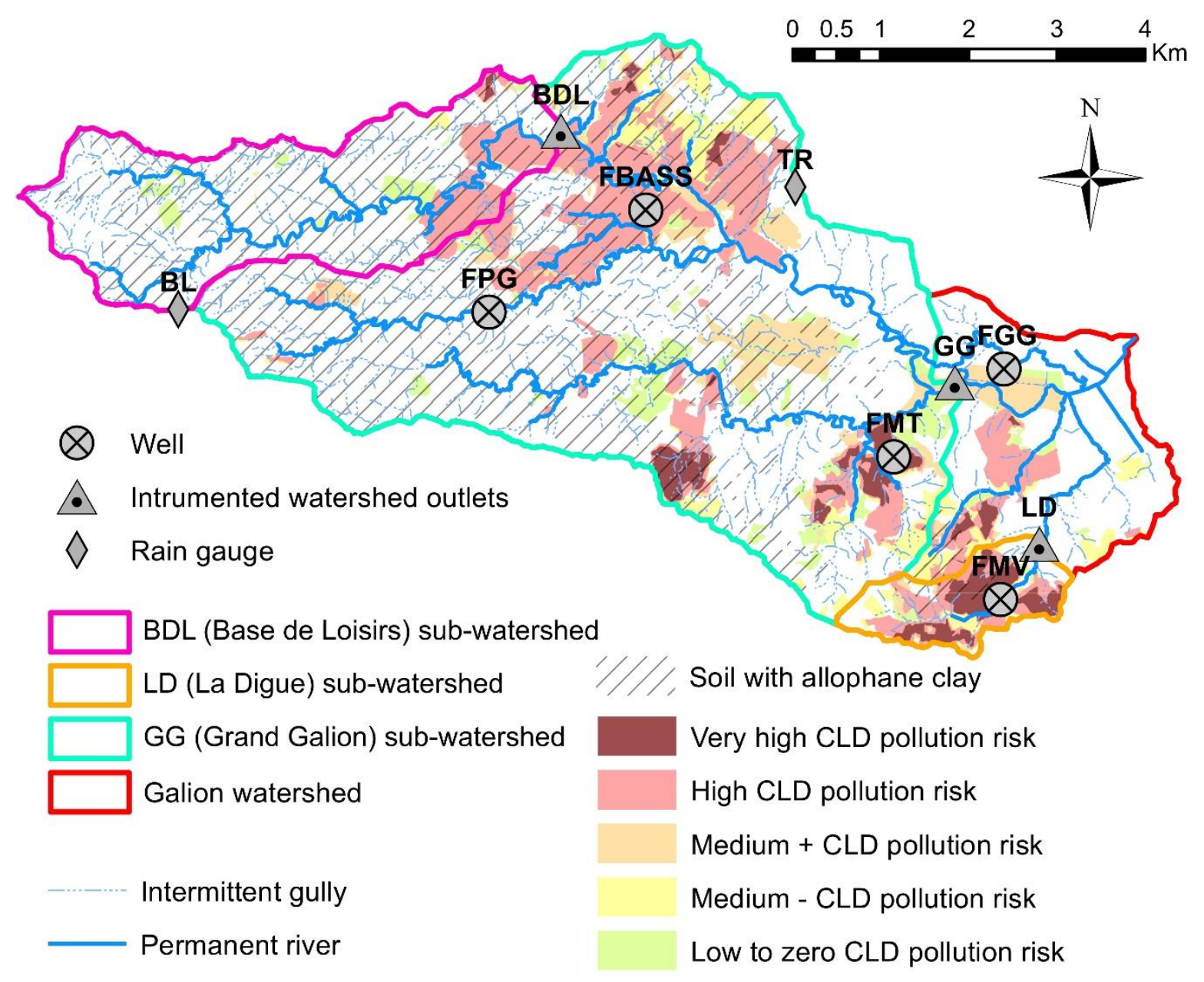

Figure 1: Map of the Galion watershed, positions of the 3 sub-watersheds, wells, rain gauges, risk of CLD pollution risk. Pollution risks following the method described in Desprats et al. (2004) and applied by Della Rossa et al. (2017).

We monitored the two sub-watersheds BDL (Base de Loisirs $-8.5 \mathrm{~km}^{2}$ ) and LD (La Digue $-1.9 \mathrm{~km}^{2}$ ) in addition to the whole GG (Grand Galion) sub-watershed that covers $35.9 \mathrm{~km}^{2}$ (Figure 1). The monitoring of the GG sub-watershed aims at representing the functioning of the whole Galion watershed with widely integrated flow from upstream to downstream. The BDL sub-watershed corresponds to the upstream watershed and its monitoring aims at representing the functioning of the upstream zone. The LD watershed is a small sub-watershed located on extremely polluted soils and its confluence with the Galion River is located downstream the GG outlet. The monitoring of LD aims at representing the functioning of small tributaries. LD has no direct hydrological connection with BDL or GG.

\subsection{Spatial variability of pollution}

The 3 monitored sub-watershed (GG, BDL and LD) have different characteristics in terms of risk of pollution (section 2.4.2). Two sub-watersheds have a majority of surface with low risk of pollution, with BDL being the less polluted: $86 \%$ with no risk, followed by GG (75\%). LD with $29 \%$ of low risks area has a majority of its area polluted (Erreur ! Source du renvoi introuvable.). Figure 1 shows that on GG, the polluted areas are mainly located in the intermediate area of the sub-watershed. They are located downstream on BDL and all over the watershed on the small LD sub-watershed because of its very large rate of polluted area. 


\begin{tabular}{llllll}
\hline & $\begin{array}{l}\text { Very high risk } \\
\mathbf{1 9 7 0 + 1 9 8 0 + 1 9 9 2}\end{array}$ & $\begin{array}{l}\text { High risk } \\
(\mathbf{1 9 7 0 0 r} \mathbf{1 9 8 0})+\mathbf{1 9 9 2}\end{array}$ & $\begin{array}{l}\text { Medium } \\
\mathbf{1 9 9 2}\end{array}$ & $\begin{array}{l}\text { Medium } \\
\mathbf{1 9 7 0}\end{array}$ & $\begin{array}{l}\text { No } \\
\text { historical } \\
\text { banana }\end{array}$ \\
\hline BDL & $0.5 \%$ & $11.3 \%$ & $0.9 \%$ & $1.1 \%$ & $86.2 \%$ \\
\hline GG & $2.2 \%$ & $14.6 \%$ & $4.9 \%$ & $3.4 \%$ & $74.9 \%$ \\
\hline LD & $29.7 \%$ & $27.6 \%$ & $3.5 \%$ & $10.5 \%$ & $28.7 \%$ \\
\hline
\end{tabular}

Table 1 : Percentage of risk of contamination for each watershed (percentage of total area)

\subsection{Hydrological monitoring and water sampling}

\subsubsection{Rainfall, hydrological and hydrogeological monitoring}

Daily rainfall for station « Bois Lézard » $(\mathrm{BL})$ and « Trinité Réservoir » (TR) were acquired from Météo France. «Bois Lézard» is located upstream and «Trinité Réservoir» midstream (see Figure 1 for locations). This combination of stations provided an overview of the rainfall gradient from up to downstream.

Discharges at the watershed outlets of BDL and LD were measured at a 3 minutes time step using a MS5 sensor (HYDROLAB $\left.{ }^{\circledR}\right)$ and recorded on DuoSens stations $\left(\right.$ OTT $\left.^{\circledR}\right)$. We gauged BDL and LD using current meter and Salinomadd $\left(\mathrm{MADD}^{\circledR}\right)$. We used the Manning-Strickler relationship based on measurement of sections of the stream to estimate discharge for high water levels.

The direction of the environment, management and housing (DEAL) from Martinique performed the GG watershed gauging and hydrological monitoring. Data are accessible through the HYDRO EauFrance website (http://www.hydro.eaufrance.fr/).

Groundwater level was recorded in 5 wells (see Figure 1 for location), equipped with automatic piezometric level recorders $\left(\right.$ OTT $\left.^{\circledR}\right)$ : Malgré Tout $($ FMT $)$ - depth $=45 \mathrm{~m}$, Mont-Vert $($ FMV) $-15 \mathrm{~m}$, Bassignac (FBASS) - $50 \mathrm{~m}$, Grand Galion (FGG) - $50 \mathrm{~m}$ and Petit Galion (FPG) $-43 \mathrm{~m}$.

\subsubsection{Water sampling in rivers and wells}

We sampled water in rivers using two different methods. A first campaign was performed in 2013 by sampling all river confluences within 5 days with punctual (one off) sampling. For more detail, the protocol is described in Della Rossa et al. (2017).

The second campaign started in February 2016. We sampled water at the 3 sub-watershed outlets (BDL, LD and GG) with a time dependent sampling protocol. To that purpose, each pollution measurement station was equipped with an automatic sampler: ISCO 6712 (ISCO Incorporation ${ }^{\circledR}$ ) sampler on BDL; Sigma SD900 (Sigma $\left.{ }^{\circledR}\right)$ sampler on GG and LD. Throughout each week, that lasted from Monday to the next Monday unless exception, the sampling frequency of each sampler was set to sample twice $100 \mathrm{~mL}$ every $1 \mathrm{~h} 15$. One sample was stored in a plastic container while the other in a glass container. Both containers were collected once a week meaning that each week the composite sample in each bottle integrated on average 135 samples. At the end of each week, we collected the two containers containing the composite samples and filled the bottles provided by the laboratory ( 3 glass bottles: $2 \times 1 \mathrm{~L}+100$ $\mathrm{mL}$ and 2 plastic bottles : $2 \times 150 \mathrm{~mL}$ totaling $2.4 \mathrm{~L}$ ) with the composite samples stored in the plastic and glass containers. Samples were collected every weeks from 01/02/2016 to 01/02/2018 and sent in ice coolers.

From October 2016 to March 2017, GG station was destroyed by a large storm (Matthew). During that period, we performed punctual sampling each week.

During our sampling Campaign, French Water Office ODE also sampled water monthly at the GG outlet. Punctual sampling was performed once a month and analyzed by LDA26 for pesticide concentration.

For groundwater, sampling was based on standard NF EN ISO 5667-3, and the FD T 90-523-3 and FD X31-615 guidelines. Before sampling in wells, at least three purge volumes were pumped with a 
submersible pump until stabilization of the chemical groundwater parameters. Samples were stored at $5^{\circ} \mathrm{C}$ and shipped in ice coolers before expedition for analysis.

\subsubsection{Chlordecone analysis}

We send the aliquots to laboratory for pesticide analysis. The selected LDA26 laboratory has been accredited by Cofrac, the French Accreditation Committee for pesticide analyzes providing guarantees for their technical skills and reliability as well as good management practices. LDA26 complies with ISO 17025 standards for testing and calibration.

Laboratory performed liquid/liquid extractions on samples. One liter of water sample was submitted to 3 extractions by using $50 \mathrm{~mL}$ of a mix of dichloromethane (80\%) and ethyl acetate (20\%). One cycle was performed at $\mathrm{pH} 7$ and two cycles at $\mathrm{pH} 2$. Extract was concentrated to $1 \mathrm{~mL}$ in ethyl acetate. The extract was then split into twice $500 \mu \mathrm{L} .500 \mu \mathrm{L}$ were use for GC MS and $500 \mu \mathrm{L}$ for HPLC MS MS. The HPLCC MS-MS was done on two transitions: 506.7/424.5 and 506.7/426.5 with a Sciex API 4000 QTRAP. Internal standards used as tracers were hexabromobenzene, tributylphosphate (added at extraction step), 2.4D3, Atrazine D5 (added at injection step) in multiple residual analysis.

The validation was done according to NFT 90210 standards. The limit of quantification was determined using six times two repetitions, the reproducibility using at least eight additions of CLD at LOQ at different dates. The trueness, recovery were estimated by using six times two additions of CLD at 3 concentrations. Uncertainty was estimated using six times two additions of CLD.

A GC quality control is performed every 20 samples at LOQ. Laboratory performed an internal calibration on 5 points before each analysis sequence. CLD addition on matrix and participation to inter laboratory comparison were also performed to control the quality of results.

CLD concentrations are given by the laboratory with a $\pm 35 \%$ error interval, a limit of quantification (LOQ) of $0.01 \mu \mathrm{g} . \mathrm{L}^{-1}$, a limit of detection (LOD) of $0.0033 \mu \mathrm{g} . \mathrm{L}^{-1}$. The extraction efficiency is $89 \%$.

\subsection{Agricultural practices and risks of soil pollution}

\subsubsection{Actual agricultural practices}

Surveys on farms located on the watersheds were performed between November 2016 and January 2016. During surveys, decision rules for practices application and plantation dates were inquired. We analyzed the evolution of fallow and crop plantations at the watershed scale using the field geographical register (RPG) from 2016 and 2017 (Direction of Agriculture And Forest of Martinique - DAAF 972). These georeferenced data describe agricultural land uses in 2016 and 2017 as declared by farmers.

\subsubsection{Mapping the risk of soil pollution}

The risk of soil pollution by CLD was estimated following the method described in Desprats et al. (2004) and applied by Della Rossa et al. (2017) on the Galion watershed. The method rely on a retrospective analysis of banana land use during the period of CLD application in Martinique (1972-1993). Soil pollution risk was classified according following rule: i) Very high risk for banana plantations present in 1970, 1980 and 1992, ii) High risk for banana plantations present for two out of the three years, iii) Medium + for banana plantations present in 1992 only, iv) Medium - for banana plantations present in 1970 only, and v) No historical banana.

\subsection{Data analysis}

We compared distributions of CLD concentrations between the two years using the non-parametric Wilcoxon Mann-Whitney test. In order to visualize CLD concentration trends, we applied a HodrickPrescott filter on the data. This filter was designed to separate long-term trends to short-term variations, suiting our need for pollutants dynamic analysis as previously applied by Sun et al. (2013). The best captures of trend were obtained with lambda parameter: $1600 \times 3^{4}$. The baseflow component of the discharge time series was calculated using the one-parameter recursive digital filter proposed by Lyne 
and Hollick (1979) implemented in the HydRun package (Tang and Carey 2017). The best capture of baseflow component of the discharge time series were acquired with parameter value of 0.8 .

\subsection{Transfers estimation}

Chlordecone mass transferred at the outlet of each instrumented watersheds was computed for each day using the formula.

$Q_{c l d}=$ WeeklyAVGCLD $*$ dailyDischarge $* \frac{3600 \times 24}{1000}$

With $Q_{c l d}$ the daily mass of CLD transferred at outlet (g), WeeklyAVGCLD, the weekly average CLD concentration in water samples ( $\left.\mu \mathrm{g} . \mathrm{L}^{-1}\right)$ and dailyDischarge the average daily discharge at sampling point $\left(\mathrm{m}^{3} \cdot \mathrm{s}^{-1}\right)$. The other term is a unit conversion factor.

We calculated the daily mass of CLD transferred at outlet per unit of polluted area (classified in low, medium-, medium+, high or very high risks) by dividing $Q_{c l d}$ by the polluted surface of each subwatershed estimated with the methodology described in 2.4.2.

\section{Results}

\subsection{Evolutions of CLD concentration in rivers}

\subsubsection{Infra-annual evolution}

Rainfall, discharge and CLD concentrations recorded on the 3 monitoring stations are presented in Figure 2. The proximity of rainfall and flood peaks for the 3 stations on a daily basis, illustrated that the watershed quickly reacted to rainfall events at the sub-watershed as well as the watershed scales. Reaction time of each watershed or sub-watershed was less than one day.
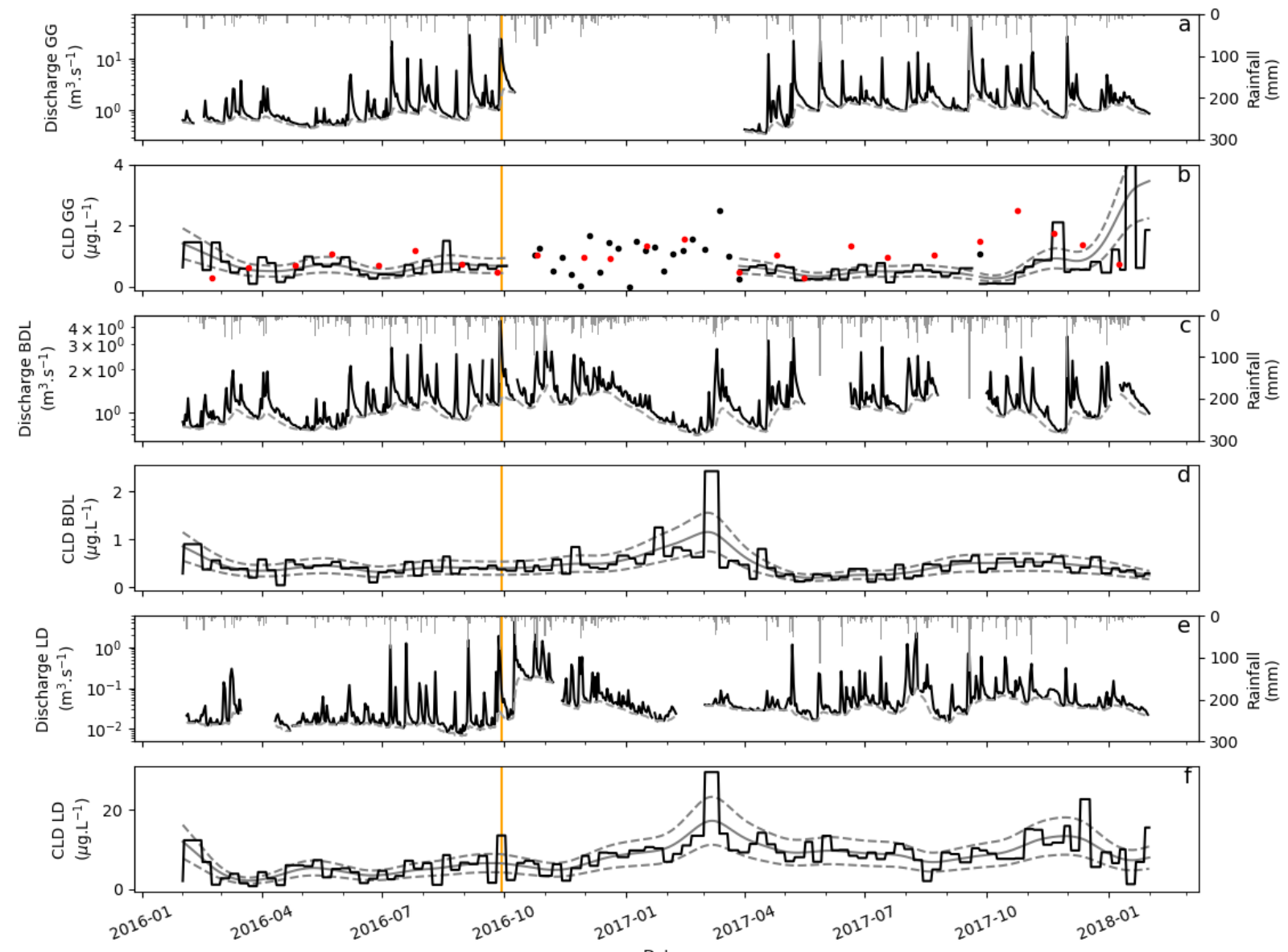
Figure 2: Hydrology and chlordecone dynamics on the 3 sampling sites of the watershed. Red dots: ODE data. Grey lines on CLD concentration graphics: Hodrick-Prescot filter and $\pm 35 \%$ error interval. Grey dashed lines on discharge graphics: baseflow. Orange vertical line: Matthew storm.

Figure $2 \mathrm{~d}$ and $2 \mathrm{f}$ shows that the trend of the CLD concentrations were correctly assessed by the HodrickPrescott filter at BDL and LD stations because most measurements fell within the $\pm 35 \%$ interval around the filtered values which correspond to the laboratory analytical uncertainty on CLD concentration measurements. Deviations from the trend may also results from shorter wavelength processes, such as flooding, sampling uncertainty, organic matter or sediments in samples. The dynamics highlighted by the filter showed patterns with period of increasing and decreasing concentrations. The up and down trends highlighted by the filter were within the same periods on BDL and LD stations. According to this result, it is likely that the dynamics we observed had a common causality. We observed that short-term increase of baseflow is associated with CLD concentration decrease on all stations, while short-term baseflow decrease are associated with CLD increase (see between 02/2016 and 09/2016 - Figure 2). During that period, CLD concentrations decrease on all station between 02/2016 and 04/2016, then it increased between 04/2016 and 05/2016, and decreased again between 05/2016 and 07/2016. This behavior corresponds to the hydrological functioning of the watershed and subwatersheds subjected to small hydrological variations where the baseflow in not subjected to changes in regimes that last more than few months. A finer analysis on the trends showed that an uptrend started few time after the "Matthew" storm (29/09/2016) when baseflow decreased and ended in March 2017. The trends were more difficult to assess on the GG station (Figure 2b) due to the lack of integrated data between 10/2016 and 03/2017 after debris transported in water few time after the Matthew storm destroyed our station. In fact, punctual sampling at that time showed high values: from 12/2016 to 04/2017 in particular, 12 punctual samples out of 15 had CLD concentrations higher than $1.1 \mu \mathrm{g} . \mathrm{L}^{-1}$ while the average concentration from $02 / 2016$ to $02 / 2018$ was $0.75 \mu \mathrm{g} . \mathrm{L}^{-1}$. The ODE follow up also suggested high CLD concentrations during that period. Starting from June, ODE data followed a bell shaped dynamic while our integrated sampling did not. In fact, concentrations measured by ODE decreased while the values of our integrated measurements increased (see 10/2017 in Figure 2b). Punctual sampling results diverged from the ones we obtained with integrated sampling indicating that CLD trends should not be easily deduced from punctual sampling at the infra-annual temporal scale.

To summarize, we identified general trends in the dynamics of CLD according to our integrated sampling. It showed a good consistency between stations LD and BDL that have no direct hydrological connection. However, we also identified that punctual weekly samples led to record high variations of concentrations. It prevents from assessing trends of CLD concentration on punctual sampling and justify assessing CLD concentrations on a weekly basis.

\subsubsection{Inter-annual evolution}

The inter-annual dynamics on LD (Figure 2f), highlighted an increase of CLD concentration in early 2017. Then, until late 2017, these concentrations remained higher than in 2016 (Table 2). Comparing average concentration between 2016 and 2017, we observed i) a slight increase of CLD average concentration on GG watershed $(+15 \%)$, ii) average concentrations on BDL that remained stable over the two years, and iii) that CLD average concentration almost doubled (+82\%) between 2016 and 2017 on the LD watershed. However, average concentrations did not reflect distribution of pollution between the two years The distributions of concentrations recorded in 2016 and 2017 were significantly different for all sub-watersheds, being highly significant for GG and LD sub-watersheds (p-value<0.001), but in a lower extent for BDL sub-watershed (p-value $<0.05$ ). This result shows that, on BDL, similar average concentration $\left(0.46 \mu \mathrm{g} . \mathrm{L}^{-1}\right)$ resulted from different river behavior in 2016 and in 2017 (significantly different distributions). Indeed, the trend analysis of BDL station showed that 2016 was characterized by a stable CLD concentration surrounding $0.46 \mu \mathrm{g} . \mathrm{L}^{-1}$, while concentrations recorded during 2017 were more variable with a CLD peak $\left(>2 \mu \mathrm{g} . \mathrm{L}^{-1}-03 / 2017\right)$ followed by an overall decrease of the concentration $\left(<0.46 \mu \mathrm{g} . \mathrm{L}^{-1}\right)$ before returning to the initial value in $10 / 2017\left(0.46 \mu \mathrm{g} . \mathrm{L}^{-1}\right)$ (Figure $\left.2 \mathrm{~d}\right)$. 
Since we noticed in section 3.1.1 that LD and BDL have CLD trends showing similarities, the high increase in mean CLD concentration in 2017 for LD stemmed, on the one hand, from two CLD peaks instead of one for BDL and, on the other hand, from higher CLD contents after the first peak relative to Matthew storm. This may be explained by the fact that the stabilized increase of CLD concentration in LD in 2017 is related to a higher baseflow level than in 2016 (Figure 2e and f). The fact that this small watershed is mainly drained by subsurface flows make it more responsive to modifications of land uses for instance. Such relationship with baseflow was not observed on BDL or GG. However, it might be that the increase of CLD concentration we observed on GG between 10/2017 and 01/2018 has the same origin but delayed in time because it is 19 times larger than LD.

\begin{tabular}{lcc}
\hline $\begin{array}{l}\text { Sampling } \\
\text { site }\end{array}$ & $\begin{array}{c}\text { CLD } \\
\text { Mean } \\
(\mathbf{2 0 1 6}) \\
\left(\boldsymbol{\mu g . L ^ { - 1 } )}\right.\end{array}$ & $\begin{array}{c}\text { CLD } \\
\text { Mean } \\
(\mathbf{2 0 1 7}) \\
\left(\boldsymbol{\mu g . L ^ { - 1 }}\right)\end{array}$ \\
\hline GG & 0.70 & 0.81 \\
\hline BDL & 0.46 & 0.46 \\
\hline LD & 5.54 & 10.08
\end{tabular}

Table 2 : Average chlordecone concentration on the 3 sampling points for the 3 sampling campaigns $(2013,2016$ and 2017).

Monitoring CLD concentrations on the 3 stations showed that CLD is a relatively stable and chronic pollution in rivers. We showed that the CLD dynamics observed in river has two components: a trend of inter-annual evolution that may be driven by baseflow as well as infra-annual variations surrounding that trended evolution whose intensities vary according to stations and may be driven by specific event like storms in the present case.

\subsubsection{Mass transfers}

The average daily CLD mass transferred at the outlet of each sub-watershed, as well as the average daily CLD mass transferred per unit of area polluted by CLD are presented in Table 3. According to Erreur ! Source du renvoi introuvable., we deduced potentially polluted area on the 3 sub-watersheds: 116 ha for BDL, 901 ha for GG and 136 ha for LD, meaning that the area between GG and BDL holds 785 potentially polluted hectares. The highest values of daily average CLD transferred at outlet were recorded on GG, while lowest values were recorded on BDL (Table 3).

\begin{tabular}{|c|c|c|c|c|c|c|}
\hline & \multicolumn{3}{|c|}{2016} & \multicolumn{3}{|c|}{2017} \\
\hline & $\begin{array}{c}\text { Daily } \\
\text { average } \\
\left(\text { g.day }^{-1}\right)\end{array}$ & $\begin{array}{l}\text { Daily average } \\
\text { per unit of } \\
\text { polluted area } \\
\left(\text { g.day }^{-1} \cdot \text { ha }^{-1}\right)\end{array}$ & $\begin{array}{c}\text { Specific } \\
\text { discharge } \\
\left(\mathrm{m}^{3} \cdot \mathrm{s}^{-1} \cdot \mathrm{km}^{-2}\right)\end{array}$ & $\begin{array}{c}\text { Daily } \\
\text { average } \\
\left(\text { g.day }^{-1}\right)\end{array}$ & $\begin{array}{l}\text { Daily average } \\
\text { per unit of } \\
\text { polluted area } \\
\left(\text { g.day }^{-1} \cdot \text { ha }^{-1}\right)\end{array}$ & $\begin{array}{c}\text { Specific } \\
\text { discharge } \\
\left(\mathrm{m}^{3} \cdot \mathrm{s}^{-1} \cdot \mathrm{km}^{-2}\right)\end{array}$ \\
\hline GG & $91 \pm 171$ & 0.10 & 0.047 & $137 \pm 303$ & 0.15 & 0.065 \\
\hline LD & $52 \pm 169$ & 0.38 & 0.052 & $68 \pm 124$ & 0.5 & 0.042 \\
\hline BDL & $49 \pm 24$ & 0.42 & 0.147 & $51 \pm 53$ & 0.44 & 0.144 \\
\hline GG-BDL & $49 \pm 159$ & 0.06 & 0.018 & $97 \pm 266$ & 0.12 & 0.027 \\
\hline
\end{tabular}

Table 3 : Chlordecone mass transferred by each watershed monitored

Table 3 shows that sub-watersheds with larger polluted area (GG and GG-BDL) are not necessarily the one that transfers the most CLD toward our monitored outlet. BDL and LD having transfers rates by polluted area 4 times higher that GG or GG-BDL (Table 3). It means that in terms of mass, the area between BDL and GG, in spite of large potentially polluted area had a lower transfer's rate to outlet. The upstream zone (represented by BDL) is humid with large rainfall and characterized by a larger specific discharge than the other sub-watersheds (Table 3). Large water volumes at relatively low CLD concentrations generated stabilized transfers at outlet as shown by the lower standard deviation than on GG or LD (Table 3). This also means that GG and LD are more subject to large variations of daily CLD mass transferred. The small specific discharge of GG-BDL also indicate that the area between GG and BDL has a small contribution to the discharge. Our results also shows that LD, in spite of its small size 

very high water CLD concentrations.

Daily mass transferred by GG gave annual values from $33 \mathrm{~kg} \cdot \mathrm{y}^{-1}$ to $50 \mathrm{~kg} \cdot \mathrm{y}^{-1}$ of CLD transferred to the Galion Bay. For LD watershed, annual value transferred to the Galion bay ranged from $19 \mathrm{~kg} \cdot \mathrm{y}^{-1}$ to 25 $\mathrm{kg} . \mathrm{y}^{-1}$. This means that the total yearly contribution of that two outlets to the Galion bay may be estimated from $50 \mathrm{kgCLD} \cdot \mathrm{y}^{-1}$ to $75 \mathrm{kgCLD} . \mathrm{y}^{-1}$. Using a simple assumption of constant transfer rate, and without considering years of applications, we estimated total transfers to the bay from 1993 to 2018 to be between $2500 \mathrm{~kg}$ and $3750 \mathrm{~kg}$. This might be even more because we did not took into account transfers from 1970 to 1993 . These amounts represent between 2.4 and $3.6 \mathrm{kgCLD}$ per ha of polluted area. This is low compared to the amount of CLD applied $\approx 3 \mathrm{~kg} \cdot \mathrm{ha}^{-1}$ at each application (Cabidoche et al. 2009; Levillain et al. 2012) during more than 20 years. Calculations of CLD stocks in soils according to Levillain et al. (2012) gave values of few $\mathrm{kg}$ of CLD stocked in soils in the 0-60 cm depth. This suggests that, it is very likely that large amounts of CLD already transferred to other environmental compartments, meaning that substantial amount of CLD could be in the marine environment and in aquifers. Because CLD was applied around banana stems and banana fields were mainly cropped on bare soils with stemflow at that period (Charlier et al. 2009) that conjointly favors surfaces transfers. It is likely that the larger fraction of CLD that lacks in our CLD balance went mainly to the marine environment during storms towards fast surface transfer processes such as runoff or subsurface flows, both concentrated in surface drains that were a very common on banana field at that time.

We showed that small watershed can nowadays have significant chlordecone transfers contributions to the ocean. In spite of the potentially large amounts of CLD that transferred in the past, we suggest that such areas with fast hydrological response should be managed with care and prioritized for pesticides reduction strategies as well as decontamination. We expect that the results of mitigation measures could be observable in the river in a couple of years for these areas.

\subsection{Evolutions of CLD in groundwaters}

Piezometric levels on the 5 wells located on the watershed and CLD concentrations recorded in 4 of these aquifers are presented in Figure 3: FPG (Fig.3b), FMT (Fig.3c), FBASS (Fig3d), FMV (Fig3e). FBASS an FMT are deep aquifers while FGG, FPG, and FMW have piezometric levels around few meters. CLD concentrations in groundwaters located in contaminated areas were 10 to 50-fold higher than concentrations measured in rivers (Figure 2 and 3). No chlordecone was found in FPG waters that is consistent with its location upstream the polluted areas (Figure 1). Based on the punctual data set, we can say that the CLD concentrations in aquifers varied along the year, but we could not define a clear relationship between CLD concentrations and piezometric levels due to the scarcity of sampling. All aquifers sampled on the 03-11-2016, at the beginning of the high water level period, had particularly high CLD concentrations. Then, CLD concentrations decreased in the following samples (Figure $3 \mathrm{~b}, \mathrm{~d}, \mathrm{e})$, but remained always in a high range of values. Besides, each aquifer had its own piezometric dynamic as shown in Figure 3. For instance, FMT had more inertial dynamic than FBASS or FMV, and even more than FGG or FPG. According to Charlier et al. (2015), the dynamic between recharge and discharge to rivers can be very long for deep aquifers with residence times from 4 years (FMV), 6 to 8 years (FMT) to more than 20 years (FBASS). 

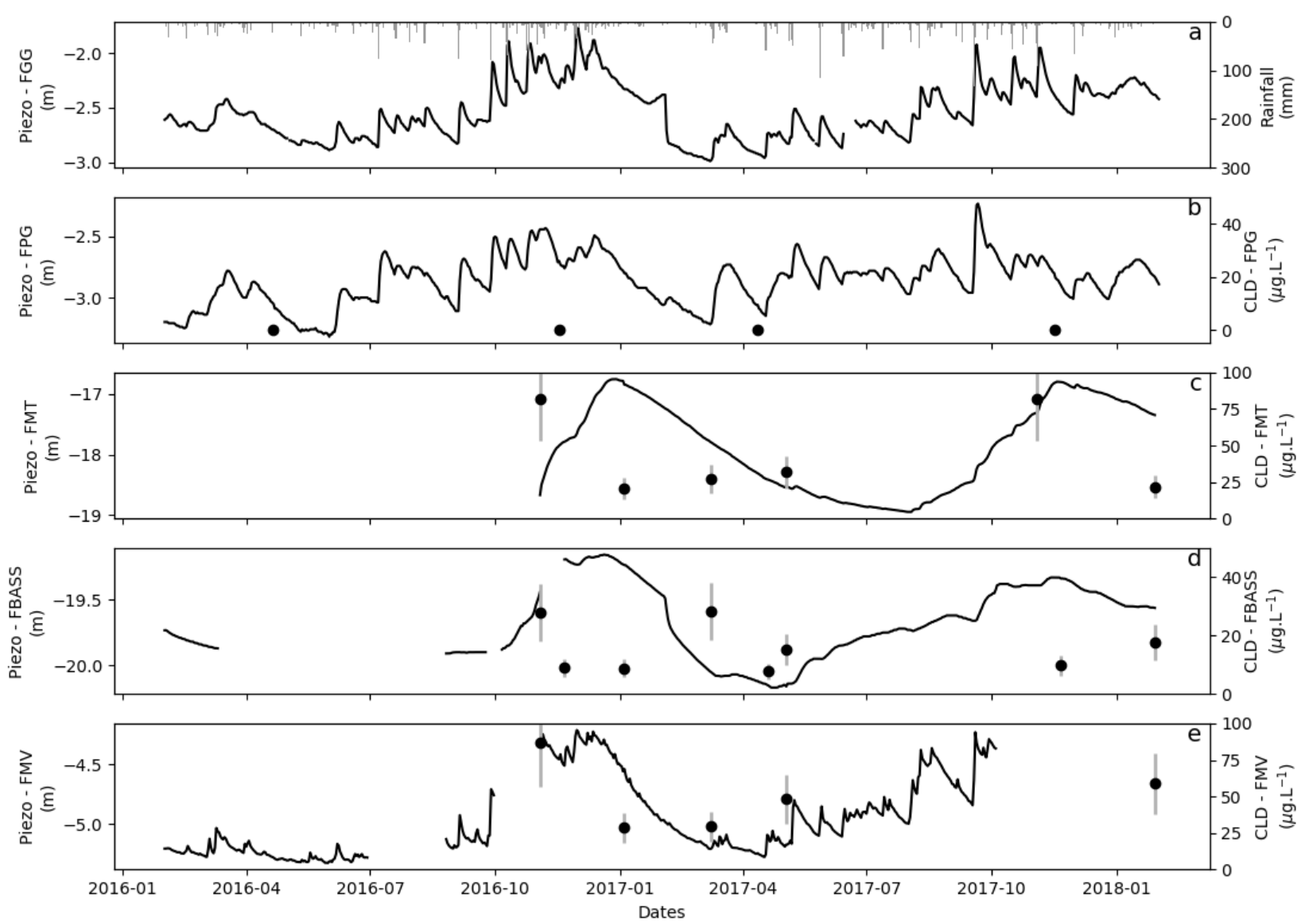

Figure 3 : Piezometric levels and CLD concentrations in aquifers of the Galion watershed. Black dots: chlordecone concentrations. Grey lines: analytical uncertainty on chlordecone concentrations.

\subsection{Evolutions of agricultural practices}

CLD polluted soil of the watershed are still mainly cropped with banana tree. This is because CLD is not quantified in banana fruit even when cropped on highly polluted soils (Clostre et al. 2017). CLD being stored into soil, several grower practices might affect CLD transfers. According to our banana grower survey, we could draw a general cropping system practiced by banana growers. Banana cropping system usually last around 7 years. During those 7 years, 5 or 6 years are indeed cropped with banana and the remaining 1 or 2 years consist in a fallow period. The fallow period allows for the soil to rest and eliminates diseases that developed in soil (nematodes and weevils) during the repeated banana cropping cycles. The fallow is established using herbicide injected into banana trees to kill them. Then, soil is tilled (Figure 4b). A fallow cover crop may either be planted, for instance with $C$. spectabilis or $B$. decumbens, or results from spontaneous species (such as C. ruditosperma). Depending on farms, at the end of the fallow period, either soil is tilled again before plantation, or banana tree are planted in a mulch of plants killed with herbicide. On the farms of the Galion watershed, tillage is usually carried on before or during the fallow period.

Figure $4 \mathrm{a}$ shows the field of one farmer of the LD watershed right after the Matthew storm. This farmer cut all developed banana tree in its farm ( 25 ha out of the 79 ha of cropped area by all farmers on the watershed) because most developed trees were laid down by the storm. 

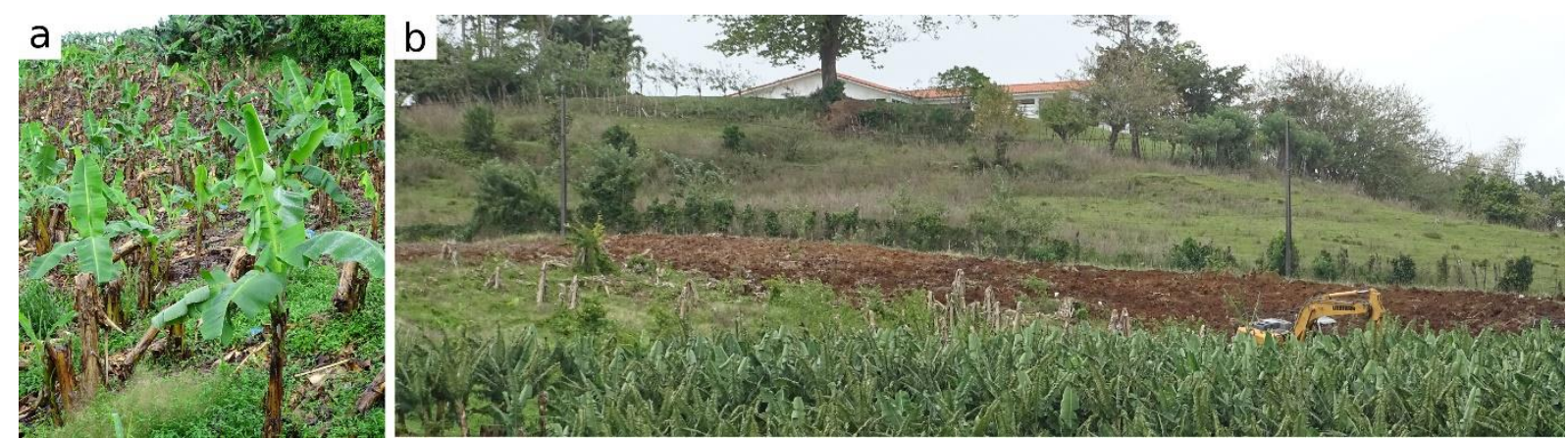

Figure 4 : a) Cycloned field just after the Matthew storm on the La Digue (LD) sub-watershed (C. Mottes Oct-2016). b) Fallow (grass with dead banana tree on the left) been tilled with excavator (bare soil) on the La Digue (LD) sub-watershed (C. Mottes Apr-2017).

Figure 5 shows fallows surface evolution between 2016 and 2017. We can see that 2017 was characterized by large increase of fallow area on the watershed that almost doubled: in 2016 fallow covered 79 ha whereas it covered 139 ha in 2017. This means that larger area than usual were tilled on the watershed between 2016 and 2017. This practice of large fallow integration after a cyclone or a violent tropical storm is a common practice among banana growers in the FWI resulting in large-scale modification of agricultural practices.

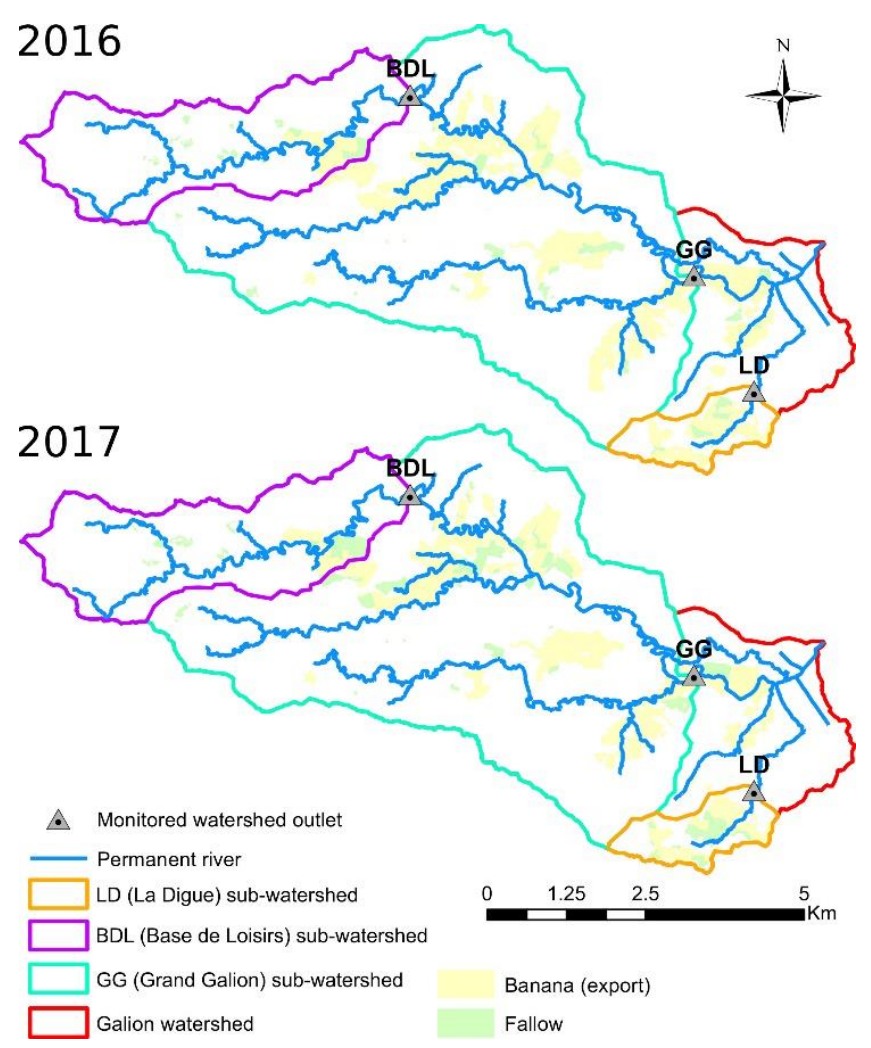

Figure 5: Evolution of fallow and banana between 2016 and 2017 (data from RPG 2016 and 2017 DAAF).

\section{Discussion}

\subsection{CLD evolutions in rivers and aquifers}

Our results showed that river and aquifer pollutions by CLD was roughly stable and chronic. Several authors have reported this (Crabit et al. 2016; Mottes et al. 2015; Mottes et al. 2017). However, CLD concentrations in rivers vary according to sites. On the small LD subwatershed, we showed that CLD interannual variability observed in river may be driven by baseflow. In the case of watersheds draining 
the highest reliefs of volcanic islands, Crabit et al. (2016) found correlation between CLD concentration and discharge because the main process of CLD evolution was the dilution of water drained from lateral cultivated areas by high amounts of unpolluted waters from the forested areas upstream. In the case of watersheds draining mostly cultivated zones, Mottes et al. (2016) did not find such relationship on the Ravine watershed, highlighting complex conditions of CLD transfers. At the watershed scale, Della Rossa et al. (2017) showed that the spatial variability of CLD concentration in water during low flow periods was explained by the potential pollution of the fields located on the watershed of the sampled points. At the regional scale, comparing numerous watersheds in Martinique Island, Cattan et al. (2019) showed that the spatial variability of CLD concentration may be explained by a combination of the location of banana cropping areas, soil and geological factors; these conditions defining a high diversity of situations in terms of the mid- to long-term duration of pollution.

Unlike previous studies, our results highlights that, at a weekly time step, CLD concentrations in rivers showed annual evolution trends (Figure 2). Aquifers located in polluted area (Figure 1) showed higher CLD concentrations during recharge (Figure 3 ) then followed by CLD uptrends in rivers (Figure 2). Figure 2 and Figure 3 analyzed conjointly showed that the uptrends we observed in rivers followed the generalized CLD peak in aquifer observed in 11/2016. Here, we are in the opinion that CLD concentration increased in aquifers and rivers as the consequence of, either translatory flow (Lischeid et al. 2002), or recent leaching of water highly concentrated with CLD. This suggests that surrounding that time, factors generated an increase of CLD leaching to aquifers and subsurface flows.

\subsection{Factors explaining increased CLD leaching}

Increased CLD leaching from soils, that is still a large reservoir of CLD (Lesueur-Jannoyer et al. 2012), to aquifers and subsurface flows is likely to have generated the increases of CLD concentrations in aquifers and rivers we observed. Several factors that increase the availability of CLD into soil to water flows can explain an increase of CLD leaching.

\subsubsection{Effect of hydroclimatic conditions}

Our results showed higher CLD concentrations on all wells situated in polluted area on the watershed at a specific date: 03-11-2016 but we could not conclude on a relationship with piezometric levels. This pattern is coherent with previous works carried out in similar hydrogeological context in Martinique Island by Arnaud et al. (2016). Based on a higher resolution of sampling (monthly), these authors showed that the intensity of piezometric fluctuations was not correlated with the amplitude of variations in CLD concentration, but that the CLD higher concentrations were often observed during periods of rising groundwater levels. Our results suggest that period of soil drying may increase the availability of CLD to water flow during the first leaching events. This is in accordance with the observations of Arnaud et al. (2016), showing that the main CLD peak in groundwaters from the last decade occurred during the first major recharge event after a several year period of deficient recharge that resulted in a very low water table. This was true for 8 wells located all over the contaminated zones of the Martinique Island, meaning that such regional pattern is likely controlled by hydroclimatic conditions. Following this explanation, we expect that the main CLD higher concentrations observed in rivers of the Galion watershed after the storm of October 2016 is related to the higher groundwater concentrations observed at that time.

\subsubsection{Effects of cropping practices}

CLD applications were forbidden after 1993, so that theoretically no applications occurred from that date. As a result, the only agricultural practices that could have increased CLD leaching are the one that modified environmental characteristics that affect pesticide transfers (Mottes et al. 2014). Here, modifications of the soil organic matter content, allophane clay content, or both potentially decreased CLD retention by soil (Woignier et al. 2016; Woignier et al. 2012a; Woignier et al. 2012b; Woignier et al. 2013). It has been shown that the peculiar hierarchical (fractal) microstructure of allophane clay traps CLD (Woignier et al. 2012a; Woignier et al. 2013). It is known that tillage activate soil organic matter 
decomposition (Haddaway et al. 2017) and expose soil to direct sunlight, hence, to strong drying at its surface resulting in destruction of allophane (Quantin 1972) and allophane microstructure. During drying, the fractal microstructure progressively disappears (Woignier et al. 2008). As a result, tillage would act on both degradation of soil organic matter and allophanes trapping properties in andosols. On top of that, tillage destroy the soil structure. The destruction of the soil structure imply a modification of the water paths into soil (Alletto et al. 2010). Indeed, structured soils present preferential infiltration flow that may be washed from extractible CLD after several time. Destroying those paths induce water to access more porosity in soil and thus extract more CLD from soil. This may explain the difference of one order of magnitude found in CLD soil organic carbon coefficients (Koc) between modelling field studies (Cabidoche et al. 2009; Mottes et al. 2015) and laboratory data (Baran and Arnaud 2013; Fernandez-Bayo et al. 2013a). In the last, soils are totally destroyed (Oecd 2000) while in the first one structured soils are considered. Finally, tillage induces modifications of soil organic matter and clay characteristics are modified as well as the soil structure. All these evolutions favor the leaching of CLD.

473

474

475

476

477

478

479

480

481

482

483

484

485

486

487

488

489

490

491

492

493

494

495

496

497

498

499

500

501

502

503

504

505

506

507

508

509

The modification of water path in soil could results from tillage but mays also results from modifications of soil covers. According to Lewis et al. (2016) and to Mottes et al. (2014) practices that modify ground cover may modify pesticide leaching. This is particularly true for vegetative ground cover such as banana tree. According to several authors, we know that banana trees concentrate rainfall along their stem by a process called stemflow (Cattan et al. 2007; Charlier et al. 2009; Sansoulet et al. 2008). This means that, in a cropped banana field, water will preferentially infiltrate right under banana tree (Cattan et al. 2007; Sansoulet et al. 2008) generating preferential flow paths under banana tree. As for structured soil, we can expect that such preferential water path are "washed" from CLD after several time of semiperennial banana cropping. Stemflow was also shown to increase runoff (Charlier et al. 2009), meaning that this process also acts on reducing the overall leaching on banana fields. Consequently, stemflow increases erosion of particulate CLD transfers as well as other surface pollutant transfers. To conclude, it means that any modification that reduce stemflow is likely to increase leaching on the field.

Our results showed that between 2016 and 2017 the surface of tilled polluted fields increased (Figure 5) on all monitored sub-watershed. Figure 1 shows that most soils of the watersheds contain allophane clay, meaning that either tillage, dry period or both could have resulted in CLD uptrend. This means that it increased the access of CLD to leaching water in 2017. Such processes could have generated increasing CLD concentration in subsurface flows thus generating uptrends in river CLD concentrations we observed on LD and BDL.

\subsection{Integration of processes at the watershed scale}

Our results showed that the different aquifers have contrasted piezometric inertia (Figure 3 ). In the Galion watershed, Charlier et al. (2015) showed variable mean residence times varying from 4 years (FMV), 6 to 8 years (FMT) to more than 20 years (FBASS). They also reported smaller residence times of one year for sources or during high water levels. Because, rivers in FWI are mainly governed by underground flows (Charlier et al. 2008; Crabit et al. 2016; Mottes et al. 2015), this means that, at the watershed scale the river is likely to be fed by different aquifer's units having different inertia. The combination of residence times and the multiplicity of aquifers contribute to the stability of CLD concentration at the weekly time step. According to our results along with the ones of Charlier et al. 2015, there is every likelihood that only underground major contributors changing conjointly may modify the trend of CLD concentration in rivers. The increased CLD concentration at LD confirms this. LD watershed is mainly governed by subsurface flow and the monitored aquifer (FMV) has a short mean residence time of 4 years, allowing it to be sensitive, among others, to strong cyclonic events. Our results showed that the mid-term CLD concentration increase in 2017 is related to the increase of the baseflow on this river (Figure 2e). According to our results, we are in the opinion that increasing CLD concentrations rely on the activation of new water paths on polluted areas on the sub-watershed.

Our results showed that in rivers, CLD concentration in punctual and integrated sampling diverged (Figure 2b). This behavior was unexpected, because we would expect to see both monitoring programs 
showing the same dynamics for a chronic pollution such as CLD. One explanations could be that CLD concentrations shows large variations with time at the event scale as it was shown for CLD (Mottes et al. 2016) and for other pesticides (Liger et al. 2012). The variability of CLD concentrations we obtained when we performed weekly punctual sampling instead of integrated sampling (between Oct 2016 and April 2017) supports that hypothesis because CLD concentration variation are very high at that period. This could mean that integrated sampling integrates the contributions of the different zones of the watersheds taking into account the delayed transfers' times according to positioning on the watershed. The CLD concentration trend we measured corresponds to the evolution of average concentrations that integrates such variability. A variable transfers time according to positioning on the watershed was suggested by Mottes et al. (2015) who included a delay in modelling CLD transfers into river according to the distance of contributing areas. On large watershed, this short-term effect might be buffered at the weekly time step or induce larger dynamics on CLD transfers. On that point, our results showed that the spatial organization of polluted fields differed in the 3 sub-watersheds, with LD being polluted on almost all its area, BDL downstream and GG mid-stream. It could be that the spatial organization of polluted area affected the CLD dynamics observed at the watershed scale (Figure 2): BDL showed uptrend followed by downtrend that could correspond to downstream contributions followed by upstream contributions. As a result, the variation of CLD concentration of punctual and integrated sampling might results from the contributions of the different transfer times of surface and subsurface flow generating a dynamics at the short to mid-time scale depending on the size of the watershed.

CLD short terms variation could also come from the fact that sediments interacts with CLD in the dissolved phase, especially in the sampling containers of our sampling stations. With automatic integrated samplers, erosion events are sampled along the week with water. As a result, sediments enters into the sampling container. They could increase CLD concentration in the sample because of CLD bound to sediments. According to ODE data, sediments analyzed at the GG station between 2008 and 2015 revealed CLD concentration varying between $<10 \mu \mathrm{g} \cdot \mathrm{kg}^{-1}$ and $30 \mu \mathrm{g} \cdot \mathrm{kg}^{-1}$. These values are low compared to soil CLD concentrations $\left(0.1-5 \mathrm{mg} \cdot \mathrm{kg}^{-1}\right)$, but could be sufficient to modify CLD concentrations in sampling containers according to the concentration value measured (Table 2) (Katagi 2006). Finally, higher variability of punctual sampling may be related to the difficulty to follow the same protocol at each sampling date. Notably sampling site may differ according to the possibilities of access to the river.

Our results suggest either that there are variability of CLD concentrations at the instant time scale or a strong interaction between dissolved and particulate phases. This means that the average concentration we obtain in weekly samples results from CLD trends, variations of CLD concentrations all over the week and from sediment dynamics in the river.

\subsection{How to manage CLD pollution?}

Our results showed that causes and processes that modify CLD concentration in water, are interrelated, making it difficult to isolate single effects. A complexity exists at the watershed scale where different organization levels and processes interact. Agricultural practices triggered according to climatic windows stand for an example of such interaction. Banana is still mainly cropped on polluted soils because it is not sensitive to soil pollution by CLD. Banana farming practices follow decision rules based on climate (cyclonic season, dry season), market.... Banana plantations increase in July to reach good price marked at the first harvest. Fallow, are largely practiced post-cyclonic after banana trees are laid down by high speed winds. Tillage is easier and recommended at medium humidity conditions corresponding to conditions of the beginning or of the end of the dry season. This means that monitoring of CLD in river will always show systemic response to event such as storm of cyclones. After them, large recharge occurs, stemflow disappear, tillage and fallow are practiced during dryer periods, all these potential causes of CLD increase have a similar triggering event, which is the storm. In a counterpart, it means that we can acts on several leeways at the watershed scale. In a mid-term objective, we recommend to integrate knowledge on pesticides transfers at different scale into modelling tools such 
as WATPPASS (Mottes et al. 2015) and to adapt their formalism to help farmers along with extension workers and decision makers to test and assess the effect of different scenarios on CLD transfers. Test the collective response of farmers at the watershed scale to specific climatic events such as storm that actually induce practice response with deleterious effects on CLD concentrations.

Our analysis showed that processes at different scale interact. Because, we cannot act on the aquifersriver relationship, we recommend focusing on limiting transfers from polluted fields. To that point, we showed that hot spots, such as LD watershed are heavy polluted by CLD resulting in large CLD concentrations in water. Such high concentration results in large amount transferred at outlet and reaching the marine environment. At the watershed scale, we recommend to focus management of transfers, on that kind of area for 3 major reasons. First, in spite of their small surface, they are large contributor to pollution transfers. Second, according to our results, such small watershed react quicky to practices and hydroclimatic conditions so that monitoring will be able to assess the positive impact of practices change on water quality. Third, they are managed by less farmers, making it easier to consistently manage all fields from the zone.

Decontamination of soils remains the final objective (Chaussonnerie et al. 2016; Mouvet et al. 2017). In the meanwhile, in terms of actions, we showed that tillage that active different processes favoring CLD transfers should be avoided as much as possible on polluted soils, or at least positioned on specific area where required such as plantation lines. To avoid pollution peaks, we recommend to avoid long drying of soils, in particular soils with allophanic clays. Maintaining a ground cover and a minimal controlled irrigation to maintain minimal hydratation could help reduce CLD peak at the end of the dry season.

Sequestration method using organic matter could be applied (Clostre et al. 2014). Using farm available organic matter, returning large amount of crop residues, the use of grass or covercrop to produce large amount of OM returned to soil, and bringing externals sources of OM from unpolluted fields could help increase OM concentration that stabilize CLD into soils.

\section{Conclusion}

We showed that CLD s concentrations vary at different spatial and time scale. The large variability of biophysical and decisional processes as well as their interactions at that scale require a systemic approach for their understanding and management. Such systemic analysis requires a local characterization of the hydrogeological functioning and of the agricultural practices to better understand losses in rivers. In the French West Indies, these involves historical CLD application, soil characteristics and the modifications by agricultural practices, and the reload conditions of aquifers defined by climatic events and the permeability of underground geological formations modulating transfers times.

\section{References}

Alletto L, Coquet Y, Benoit P, Heddadj D, Barriuso E (2010) Tillage management effects on pesticide fate in soils. A review Agron Sustain Dev 30:367-400 doi:10.1051/agro/2009018

Arnaud L, Charlier J-B, Ducreux L, A.-L. T (2016) Groundwater Quality Assessment. In: LesueurJannoyer M, Cattan P, Woignier T, Clostre F (eds) Crisis Management of Chronic Pollution: Contaminated Soil and Human Health. CRC Press, Boca Raton, pp 55-72

Baran N, Arnaud L (2013) Mapping of groundwater risks of contamination by pesticides in Martinique, BRGM (in French)

Cabidoche YM, Achard R, Cattan P, Clermont-Dauphin C, Massat F, Sansoulet J (2009) Long-term pollution by chlordecone of tropical volcanic soils in the French West Indies: A simple leaching model accounts for current residue Environ Pollut 157:1697-1705 doi:10.1016/j.envpol.2008.12.015

Cattan P, Cabidoche Y, Lacas J, Voltz M (2006) Effects of tillage and mulching on runoff under banana (Musa spp.) on a tropical Andosol Soil and Tillage Research 86:38-51 doi:10.1016/j.still.2005.02.002 
Cattan P, Charlier JB, Clostre F, Letourmy P, Arnaud L, Gresser J, Jannoyer M (2019) A conceptual model of organochlorine fate from a combined analysis of spatial and mid- to long-term trends of surface and ground water contamination in tropical areas (FWI) Hydrol Earth Syst Sci 23:691-709 doi:10.5194/hess-23-691-2019

Cattan P, Voltz M, Cabidoche YM, Lacas JG, Sansoulet J (2007) Spatial and temporal variations in percolation fluxes in a tropical Andosol influenced by banana cropping patterns $\mathbf{J}$ Hydrol 335:157-169 doi:16/j.jhydrol.2006.11.009

Charlier J-B, Cattan P, Moussa R, Voltz M (2008) Hydrological behaviour and modelling of a volcanic tropical cultivated catchment Hydrol Process 22:4355-4370 doi:10.1002/hyp.7040

Charlier J-B, Lachassagne P, Ladouche B, Cattan P, Moussa R, Voltz M (2011) Structure and hydrogeological functioning of an insular tropical humid andesitic volcanic watershed: A multidisciplinary experimental approach J Hydrol 398:155-170 doi:10.1016/j.jhydrol.2010.10.006

Charlier JB, Arnaud L, Ducreux L, Ladouche B, Dewandel B (2015) CHLOR-EAU-SOL - Water Caracterization of water and soil contamination by chlordecone of watersheds in Guadeloupe and Martinique. Final report. BRGM (in French)

Charlier JB, Moussa R, Cattan P, Cabidoche YM, Voltz M (2009) Modelling runoff at the plot scale taking into account rainfall partitioning by vegetation: application to stemflow of banana (Musa spp.) plant Hydrol Earth Syst Sci 13:2151-2168 doi:10.5194/hess-13-2151-2009

Chaussonnerie S, Saaidi P-L, Ugarte E, Barbance A, Fossey A, Barbe V, Gyapay G, Brüls T, Chevallier M, Couturat L, Fouteau S, Muselet D, Pateau E, Cohen GN, Fonknechten N, Weissenbach J, Le Paslier D (2016) Microbial Degradation of a Recalcitrant Pesticide: Chlordecone Frontiers in Microbiology 7:2025 doi:10.3389/fmicb.2016.02025

Clostre F, Cattan P, Gaude JM, Carles C, Letourmy P, Lesueur-Jannoyer M (2015) Comparative fate of an organochlorine, chlordecone, and a related compound, chlordecone-5b-hydro, in soils and plants Sci Total Environ 532:292-300 doi:10.1016/j.scitotenv.2015.06.026

Clostre F, Letourmy P, Lesueur-Jannoyer M (2017) Soil thresholds and a decision tool to manage food safety of crops grown in chlordecone polluted soil in the French West Indies Environ Pollut 223:357-366 doi:10.1016/j.envpol.2017.01.032

Clostre F, Woignier T, Rangon L, Fernandes P, Soler A, Lesueur-Jannoyer M (2014) Field validation of chlordecone soil sequestration by organic matter addition Journal of Soils and Sediments 14:23-33 doi:10.1007/s11368-013-0790-3

Crabit A, Cattan P, Colin F, Voltz M (2016) Soil and river contamination patterns of chlordecone in a tropical volcanic catchment in the French West Indies (Guadeloupe) Environ Pollut 212:615626 doi:http://dx.doi.org/10.1016/j.envpol.2016.02.055

Della Rossa P, Jannoyer M, Mottes C, Plet J, Bazizi A, Arnaud L, Jestin A, Woignier T, Gaude J-M, Cattan P (2017) Linking current river pollution to historical pesticide use: Insights for territorial management? Sci $\quad$ Total Environ $574: 1232-1242$ doi:http://dx.doi.org/10.1016/j.scitotenv.2016.07.065

Desprats JF, Comte JP, Charbier C (2004) Mapping of the risk of soil pollution by organochlorine pesticides in Martinique. BRGM (in French)

Devault DA, Laplanche C, Pascaline H, Bristeau S, Mouvet C, Macarie H (2016) Natural transformation of chlordecone into 5b-hydrochlordecone in French West Indies soils: statistical evidence for investigating long-term persistence of organic pollutants Environmental Science and Pollution Research 23:81-97 doi:10.1007/s11356-015-4865-0

Dorel M, Roger-Estrade J, Manichon H, Delvaux B (2000) Porosity and soil water properties of Caribbean volcanic ash soils Soil Use Manag 16:133-140 doi:10.1111/j.14752743.2000.tb00188.x

Dromard CR, Guéné M, Bouchon-Navaro Y, Lemoine S, Cordonnier S, Bouchon C (2018) Contamination of marine fauna by chlordecone in Guadeloupe: evidence of a seaward decreasing gradient Environmental Science and Pollution Research 25:14294-14301 doi:10.1007/s11356-017-8924-6

Fernandez-Bayo JD, Saison C, Geniez C, Voltz M, Vereecken H, Berns AE (2013a) Sorption characteristics of chlordecone and cadusafos in tropical agricultural soils Current Organic Chemistry 17:2976-2984 
Fernandez-Bayo JD, Saison C, Voltz M, Disko U, Hofmann D, Berns AE (2013b) Chlordecone fate and mineralisation in a tropical soil (andosol) microcosm under aerobic conditions The Science of the total environment 463-464 doi:10.1016/j.scitotenv.2013.06.044

Germa A, Quidelleur X, Labanieh S, Chauvel C, Lahitte P (2011) The volcanic evolution of Martinique Island: Insights from $\mathrm{K}-\mathrm{Ar}$ dating into the Lesser Antilles arc migration since the Oligocene Journal of Volcanology and Geothermal Research 208:122-135 doi:https://doi.org/10.1016/j.jvolgeores.2011.09.007

Gourcy L, Baran N, Vittecoq B (2009) Improving the knowledge of pesticide and nitrate transfer processes using age-dating tools (CFC, SF6, 3H) in a volcanic island (Martinique, French West Indies) Journal of Contaminant Hydrology 108:107-117 doi:10.1016/j.jconhyd.2009.06.004

Haddaway NR, Hedlund K, Jackson LE, Kätterer T, Lugato E, Thomsen IK, Jørgensen HB, Isberg P-E (2017) How does tillage intensity affect soil organic carbon? A systematic review Environmental Evidence 6:30 doi:10.1186/s13750-017-0108-9

Katagi T (2006) Behavior of pesticides in water-sediment systems Reviews of Environmental Contamination and Toxicology 187:133-251

Lesueur-Jannoyer M, Cattan P, Monti D, Saison C, Voltz M, Woignier T, Cabidoche YM (2012) Chlordecone aux Antilles : evolution des systemes de culture et leur incidence sur la dispersion de la pollution Agronomie, environnement et societes 2:45-58

Levillain J, Cattan P, Colin F, Voltz M, Cabidoche Y-M (2012) Analysis of environmental and farming factors of soil contamination by a persistent organic pollutant, chlordecone, in a banana production area of French West Indies Agric Ecosyst Environ 159:123-132 doi:10.1016/j.agee.2012.07.005

Lewis SE, Silburn DM, Kookana RS, Shaw M (2016) Pesticide Behavior, Fate, and Effects in the Tropics: An Overview of the Current State of Knowledge J Agric Food Chem 64:3917-3924 doi:10.1021/acs.jafc.6b01320

Liger L, Carluer N, Coquery M, Gouy V, Guillemain C, Margoum C (2012) Comparison of different active sampling strategies for monitoring pesticide pollutions in surface waters. In: 42e congrès du Groupe Français des Pesticides, Poitiers, France, 2012-05-30. 7p. (in French)

Lischeid G, Kolb A, Alewell C (2002) Apparent translatory flow in groundwater recharge and runoff generation J Hydrol 265:195-211 doi:https://doi.org/10.1016/S0022-1694(02)00108-7

Lyne V, Hollick M Stochastic time-variable rainfall-runoff modelling. In: Institute of Engineers Australia National Conference, 1979. Institute of Engineers Australia Barton, Australia, pp 8993

Méndez-Fernandez P, Kiszka JJ, Heithaus MR, Beal A, Vandersarren G, Caurant F, Spitz J, Taniguchi S, Montone RC (2018) From banana fields to the deep blue: Assessment of chlordecone contamination of oceanic cetaceans in the eastern Caribbean Mar Pollut Bull 137:56-60 doi:https://doi.org/10.1016/j.marpolbul.2018.10.012

Mottes C, Charlier JB, Rocle N, Gresser J, Lesueur-Jannoyer M, Cattan P (2016) From fields to rivers chlordecone transfer in water. In: Lesueur-Jannoyer M, Cattan P, Woignier T, Clostre F (eds) Crisis Management of Chronic Pollution: Contaminated Soil and Human Health. CRC Press, Boca Raton, pp 121-130

Mottes C, Lesueur-Jannoyer M, Charlier J-B, Carles C, Guéné M, Le Bail M, Malézieux E (2015) Hydrological and pesticide transfer modeling in a tropical volcanic watershed with the $\begin{array}{lllll}\text { WATPPASS model J H } & \text { Hydrol } & \text { 509-927 }\end{array}$ doi:http://dx.doi.org/10.1016/j.jhydrol.2015.09.007

Mottes C, Lesueur-Jannoyer M, Le Bail M, Malézieux E (2014) Pesticide transfer models in crop and watershed systems: a review Agron Sustain Dev 34:229-250 doi:10.1007/s13593-013-0176-3

Mottes C, Lesueur Jannoyer M, Le Bail M, Guene M, Carles C, Malezieux E (2017) Relationships between past and present pesticide applications and pollution at a watershed outlet: The case of a horticultural catchment in Martinique, French West Indies Chemosphere 184:762-773 doi:10.1016/j.chemosphere.2017.06.061

Mouvet C, Dictor M-C, Bristeau S, Breeze D, Mercier A (2017) Remediation by chemical reduction in laboratory mesocosms of three chlordecone-contaminated tropical soils Environmental Science and Pollution Research 24:25500-25512 doi:10.1007/s11356-016-7582-4 
Multigner L, Kadhel P, Rouget F, Blanchet P, Cordier S (2016) Chlordecone exposure and adverse effects in French West Indies populations Environmental Science and Pollution Research 23:38 doi:10.1007/s11356-015-4621-5

Oecd (2000) Test No. 106: Adsorption-desorption using a batch equilibrium method. Organisation for Economic Co-operation and Development, Paris

Quantin P (1972) Les Andosols - Revue bibliographique des connaissances actuelles Cah ORSTOM 10:273-302

Ranguin R, Durimel A, Karioua R, Gaspard S (2017) Study of chlordecone desorption from activated carbons and subsequent dechlorination by reduced cobalamin Environmental Science and Pollution Research 24:25488-25499 doi:10.1007/s11356-017-9542-z

Sansoulet J, Cabidoche Y-M, Cattan P, Ruy S, Šimůnek J (2008) Spatially Distributed Water Fluxes in an Andisol under Banana Plants: Experiments and Three-Dimensional Modeling Vadose Zone Journal 7 doi:10.2136/vzj2007.0073

Sun CC, Shen ZY, Xiong M, Ma FB, Li YY, Chen L, Liu RM (2013) Trend of dissolved inorganic nitrogen at stations downstream from the Three-Gorges Dam of Yangtze River Environ Pollut 180:13-18 doi:https://doi.org/10.1016/j.envpol.2013.05.003

Tang W, Carey SK (2017) Hyd R un: A MATLAB toolbox for rainfall-runoff analysis Hydrol Process 31:2670-2682

Vittecoq B, Reninger PA, Violette S, Martelet G, Dewandel B, Audru JC (2015) Heterogeneity of hydrodynamic properties and groundwater circulation of a coastal andesitic volcanic aquifer controlled by tectonic induced faults and rock fracturing - Martinique island (Lesser Antilles FWI) J Hydrol 529:1041-1059 doi:https://doi.org/10.1016/j.jhydrol.2015.09.022

Woignier T, Clostre F, Fernandes P, Rangon L, Soler A, Lesueur-Jannoyer M (2016) Compost addition reduces porosity and chlordecone transfer in soil microstructure Environmental Science and Pollution Research 23:98-108 doi:10.1007/s11356-015-5111-5

Woignier T, Clostre F, Macarie H, Jannoyer M (2012a) Chlordecone retention in the fractal structure of volcanic clay Journal of hazardous materials 241-242:224-230 doi:10.1016/j.jhazmat.2012.09.034

Woignier T, Fernandes P, Jannoyer-Lesueur M, Soler A (2012b) Sequestration of chlordecone in the porous structure of an andosol and effects of added organic matter: an alternative to decontamination Eur J Soil Sci 63:717-723 doi:10.1111/j.1365-2389.2012.01471.x

Woignier T, Fernandes P, Soler A, Clostre F, Carles C, Rangon L, Lesueur-Jannoyer M (2013) Soil microstructure and organic matter: Keys for chlordecone sequestration Journal of Hazardous Materials 262:357-364 doi:10.1016/j.jhazmat.2013.08.070

Woignier T, Primera J, Duffours L, Dieudonné P, Raada A (2008) Preservation of the allophanic soils structure by supercritical drying Microporous and Mesoporous Materials 109:370-375 doi:https://doi.org/10.1016/j.micromeso.2007.05.019 